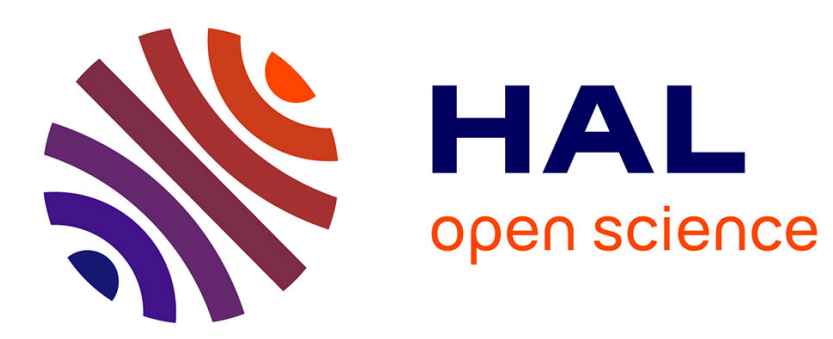

\title{
Prediction of failure probability of large unidirectional fibre reinforced composites
}

\author{
M. Lienkamp, H.-E. Exner
}

\section{To cite this version:}

M. Lienkamp, H.-E. Exner. Prediction of failure probability of large unidirectional fibre reinforced composites. Journal de Physique IV Proceedings, 1993, 03 (C7), pp.C7-1601-C7-1606. 10.1051/jp4:19937251 . jpa-00251890

\section{HAL Id: jpa-00251890 https://hal.science/jpa-00251890}

Submitted on 1 Jan 1993

HAL is a multi-disciplinary open access archive for the deposit and dissemination of scientific research documents, whether they are published or not. The documents may come from teaching and research institutions in France or abroad, or from public or private research centers.
L'archive ouverte pluridisciplinaire HAL, est destinée au dépôt et à la diffusion de documents scientifiques de niveau recherche, publiés ou non, émanant des établissements d'enseignement et de recherche français ou étrangers, des laboratoires publics ou privés. 


\title{
Prediction of failure probability of large unidirectional fibre reinforced composites
}

\author{
M. LIENKAMP and H.-E. EXNER
}

Technical University of Darmstadt, Department of Materials Science, Petersenstr. 30, 64287 Darmstadt, Germany

\begin{abstract}
Tensile strength data obtained from measurement of small test specimens cannot be easily extrapolated to large composite structures. A statistical model is proposed which predicts the strength of composites from the properties of their constituents. It is assumed that with increasing load fibres fail at their most severe flaws and overload adjacent fibres and larger clusters of broken fibres develop locally. At a certain size cluster growth gets critical, i.e. the composite fails. The probability of formation of one cluster of the critical size characterises the failure probability of the composite. Three different local load sharing rules are compared. The predicted composite strength is insensitive to the chosen local load sharing rule.

A parametric study for different Weibull moduli of the fibres, different sizes and failure probabilities of the composite is conducted. The critical cluster size and the tensile strength of the composite are predicted.
\end{abstract}

\section{INTRODUCTION}

The problem of predicting the tensile strength of low stiffness matrices reinforced with unidirectionally oriented fibres from the properties of the fibre, the matrix and their interface has not been completely solved yet. Early attempts have been made to apply rules of mixtures for predicting the tensile strength of a composite by averaging over the strength of its constituents [1]. This approach neglects that fibres have a strength distribution and that there is a complex process of crack initiation, load transfer and fibre interaction. A first statistical model for describing composite strength was proposed by Rosen [2].

Later models include local load sharing at broken fibres [3-8], i.e. the load of broken fibres is not distributed onto all surviving fibres, but only onto adjacent fibres in the plane of the broken fibre. The size of the simulated array is usually orders of magnitude below the size of the actual composite [3-7] or the simulated fibre arrangement of the composite does not correspond to the real one [3,7]. Other models use extremely simple load sharing rules and are not able to predict the strength at certain failure probabilities [8].

\section{MODEL FOR COMPOSITE STRENGTH}

A worst case model is proposed which overcomes some of the limitations of the earlier models and is able to estimate the failure probability of large composites. The model uses the chain-of-bundles model [2], a local load sharing rule [5] with an approach based on a shear lag analysis [9], and an arbitrary large amount of lattice points. The fibre strength is assumed to follow a Weibull distribution [10]. It can be determined from single fibre tests [ASTM 3379] or from a single bundle test [11,12]

We consider a hexagonal array of parallel fibres embedded in a low stiffness matrix, having a breaking elongation higher than that of the fibres. The composite has no flaws, delaminations, predamages, etc. It is extended in tension and a uniform stress in the fibres is induced. With increasing load some fibres fail at their most severe flaws. 


\section{Critical length}

When a fibre in a composite fails it is not lost for the composite. The load at broken fibre ends recovers over a certain length called critical length $l_{\mathrm{c}}$. Over this length adjacent fibres are overloaded. The equivalent critical length $l_{e}$ is the length of a fibre carrying a constant overload and having the same failure probability as a fibre carrying an increasing overload (figure 1). The equivalent critical length $l_{e}$ depends on the fibre matrix combination and the interface and can be determined by several methods [13].

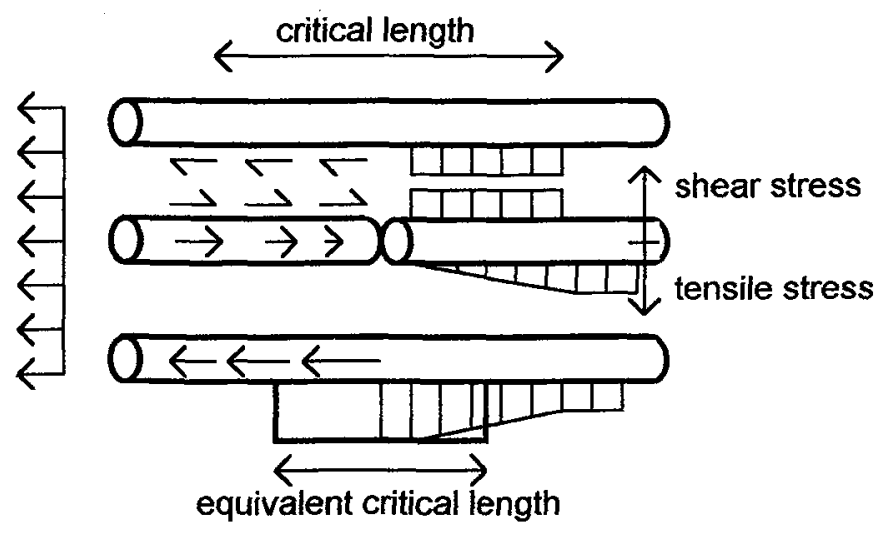

Figure 1:

Load transfer from broken fibres to adjacent fibres through shear stresses in the matrix.

\section{ChaIN-OF-BUNDLES MODEL}

Following the chain-of-bundles model [2] the composite is devided into $\mathrm{m}$ statistically independent bundles in fibre direction. Each bundle is of the equivalent critical length $l_{e}$ and contains $n$ fibre elements. Since the portion of surface fibres is very low for bulk composites, edge effects can be neglected. This allows to consider the composite as an arrangement of $m$ times $n$ fibre elements.

\section{LOCAL LOAD SHARING RULE}

Hedgepeth [9] calculated the overload factors for surviving fibres adjacent to broken fibres for a hexagonal fibre arrangement. A key assumption of the derivation is a low stiffness matrix, which only serves to transfer shear stresses. In order to reduce the computational effort the load sharing is simplified by distributing the load of broken fibres equally onto the nearest surviving neighbours [5]. If all adjacent fibres are broken, the load is equally distributed onto the surviving second nearest neighbours. The so called geometric load sharing rule leads to a worse load sharing than the one proposed by Hedgepeth [9]. The calculated strength of the composite is lower, thus the prediction is conservative. Three different load sharing rules are used:

Geometric load sharing 1:

Only the fibres which carry the highest overload according to the above mentioned geometrical load sharing are considered. All other adjacent fibres will not fail. This load sharing represents the major crack path assumption, i.e. the crack will only propagate by the failure of the fibres carrying the highest overload. A simple example for the overload due to broken fibres is shown in figure 2. Overload factors for larger clusters are given in [5].

Geometric load sharing 2:

This rule represents the maximum effect of multiple failure paths. It is assumed that every break of an overloaded fibre leads again to a compact cluster even though some fibre breaks would lead to a cluster which spreads out. Since the load sharing for compact clusters is worse than the one for clusters which spread out this is a conservative assumption in terms of composite strength. 
In order to reduce the computational effort only the overload factors $K_{1}, K_{2}$ and $K_{3}$, and the number of overloaded fibres at this overload $S_{1}, S_{2}$ and $S_{3}$ are used [14]. The overload factors $K_{1}$ and $K_{2}$ are calculated by the geometrical load sharing rule. The load not yet accounted for is equally distributed onto the rest of the neighbour fibres $S_{3}$. With $S_{2}$, the number of fibres adjacent to the broken cluster of fibres and $k$, the number of broken fibres in the cluster, we get

$$
\begin{aligned}
& S_{3}=S_{a}-S_{1}-S_{2} \\
& K_{3}=1+\left(k-\left(K_{1}-1\right) S_{1}-\left(K_{2}-1\right) S_{2}\right) / S_{3}
\end{aligned}
$$

Simple load sharing:

It is assumed that the load of the broken fibres of a cluster is equally redistributed onto all surviving adjacent fibres. Every break of an overloaded fibre leads again to a compact cluster.

Global load sharing:

The load of broken fibres is redistributed onto all surviving fibres in the cross section [15]. The global load sharing characterises the upper limit of the strength of a composite.
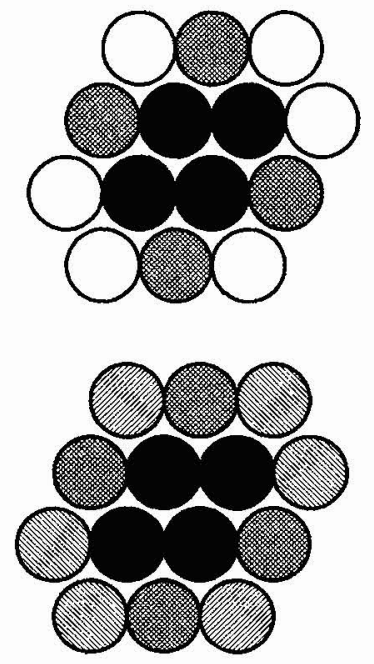

geometric 1

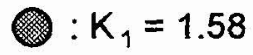

geometric 2

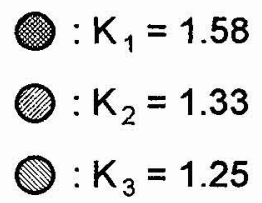

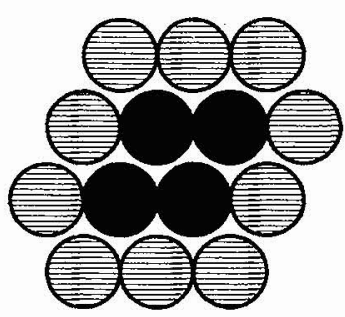

simple

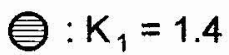

Figure 2:

Overload factors, $\mathrm{K}_{\mathrm{i}}$ for four broken fibres for two different geometric load sharing rules and a simple load sharing rule.

Figure 3 shows the composite strength $\left(\mathrm{mn}=10^{9}, \rho=8\right)$ calculated with the statistical model described in detail below for the three different local load sharing rules and the global load sharing rule. The composite strength is normalized to the fibre strength at the equivalent critical length and to the fibre volume fraction $\sigma /\left(\sigma_{0}\left(l_{e}\right) V_{F}\right)$. As expected the composite strength calculated with the geometric 1 rule is higher than the one predicted with the geometric 2 rule. The composite strength calculated by using the simple rule is in between the geometric rules. However, the differences of the calculated composite strengths are little. This means firstly that the predicted composite strength is insensitive to the local load sharing rule chosen. Secondly the critical cluster develops most likely through the major crack path, i.e. due to breaks of the fibres carrying the highest overload. Other failure paths contribute only little to the failure.

In order to present a worst case model the following results are obtained using the geometric 2 load sharing rule. 


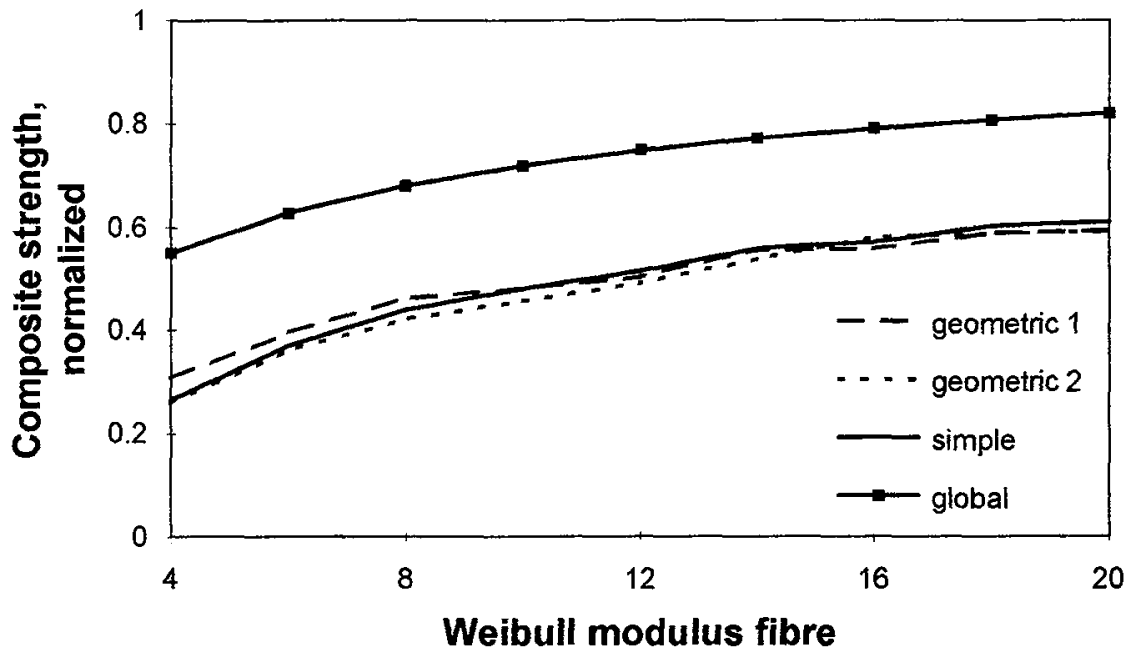

Figure 3:

Composite strength versus Weibull modulus of fibres for different load sharing rules.

\section{FAILURE CRITERION}

With increasing stress single fibre breaks (singlets) occur in the composite [8]. Stress concentrations lead to further fibre breaks, i.e. pairs of broken fibres or diplets. The number of diplets $\mathrm{C}_{2}$ is the number of $\sin$ glets $\mathrm{C}_{1}$ times the probability that a second fibre adjacent to the broken fibre breaks (failure probability of overloaded fibre times number of overloaded fibres):

$$
\mathrm{C}_{\mathrm{k}+1}=\mathrm{C}_{\mathrm{k}} \sum_{\mathrm{i}=1}^{3} \mathrm{~S}_{\mathrm{ki}}\left(1-\exp \left(-\frac{1}{1_{\mathrm{e}}}\left(\frac{\mathrm{K}_{\mathrm{k}} \sigma}{\sigma_{0}}\right)^{\rho}\right)\right), \mathrm{k}=0 \ldots 19
$$

( $S_{\mathrm{ki}}$ : number of fibres overloaded by $K_{\mathrm{ki}} \sigma, K_{\mathrm{ki}}$ : overload factor).

Starting with $\mathrm{C}_{0}=\mathrm{mn}$ the calculation is conducted up to a cluster size of 20 . The numbers of clusters grow with increasing load. At a certain stress the number of clusters of a size $k+1$ gets higher than the number of clusters of the size $\mathrm{k}$. This means that each cluster of the size $\mathrm{k}$ transforms into a cluster of the size $\mathrm{k}+1$, i.e. the cluster growth becomes unstable and the composite fails catastrophically. This cluster size is named the critical cluster size $\mathrm{k}^{*}$ (equivalent to the Griffith concept of the critical crack size in brittle materials). The probability of formation of one cluster of the critical size characterises the probability of failure of the composite.

\section{RESULTS}

As an example a tensile rod is considered with a size of $\mathrm{lht}=100 \times 10 \times 10 \mathrm{~mm}^{3}$ made of carbon fibres embedded in a low stiffness epoxy matrix. The diameter of the fibres is $d=6 \mu \mathrm{m}$ and the fibre volume contents $V_{F}=70 \%$. With $l_{e}=0.25 \mathrm{~mm}$ the number of fibre segments in the rod is approximately $\mathrm{mn}=10^{9}$.

$$
m n=\frac{1}{l_{e}} h t V_{F} \frac{4}{\pi d^{2}}
$$

The Weibull modulus is $p=8$. In order to predict the failure probability at certain stresses the number of the different clusters is plotted in a Weibull diagram (figure 4). The stress is normalized to $\sigma_{0}\left(l_{e}\right) V_{F}$. This plot correlates the probability of forming a critical cluster to the failure probability of the composite. The slope of the lines of the broken clusters is k times $\rho$. At a certain failure probability $P$ the composite fails if there is no larger cluster at higher loads, i.e. if every critical cluster transforms into a larger one. The composite does not have a single Weibull modulus. The slope of the failure envelope is only piece wise constant. 


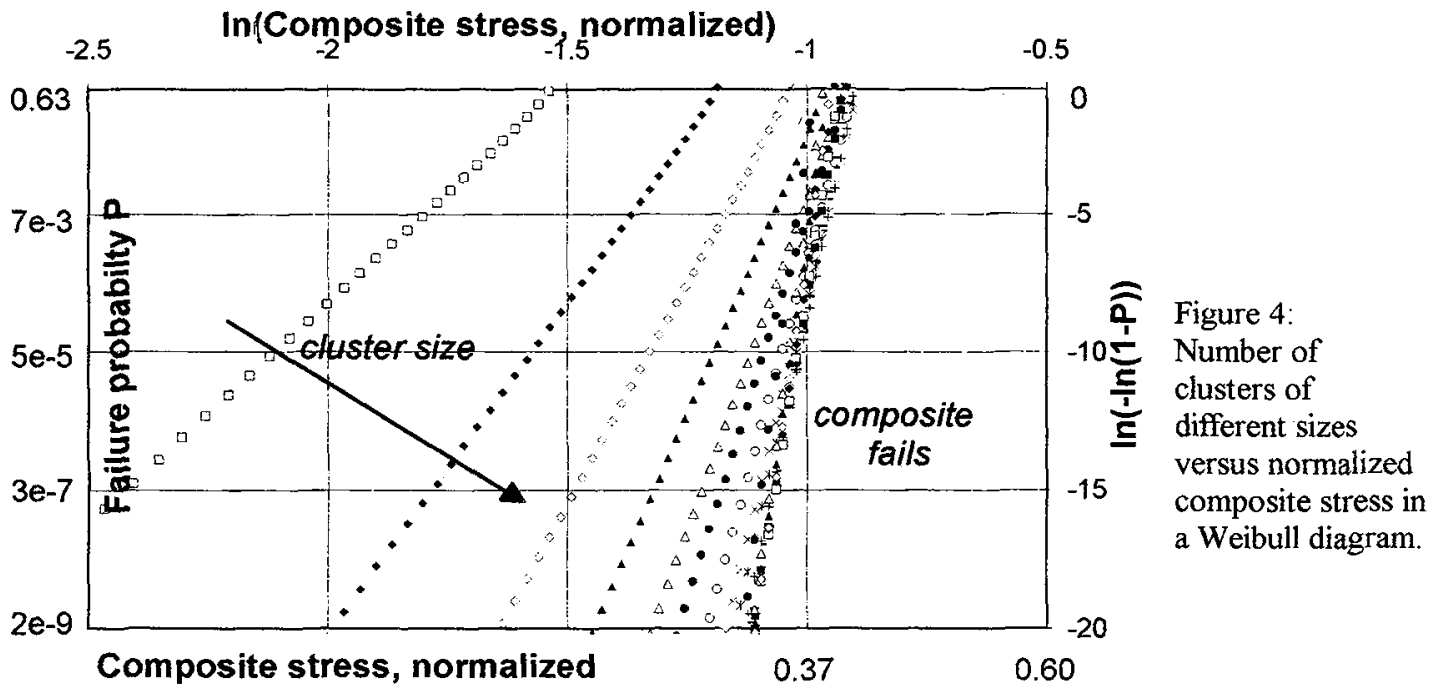

\section{PARAMETRIC STUDY}

Figure 5 shows the normalized strength of the composite for different composite sizes and different failure probabilities as a function of the Weibull modulus of the fibres. Lower fibre strength variability and smaller composite size leads to a composite of higher strength.

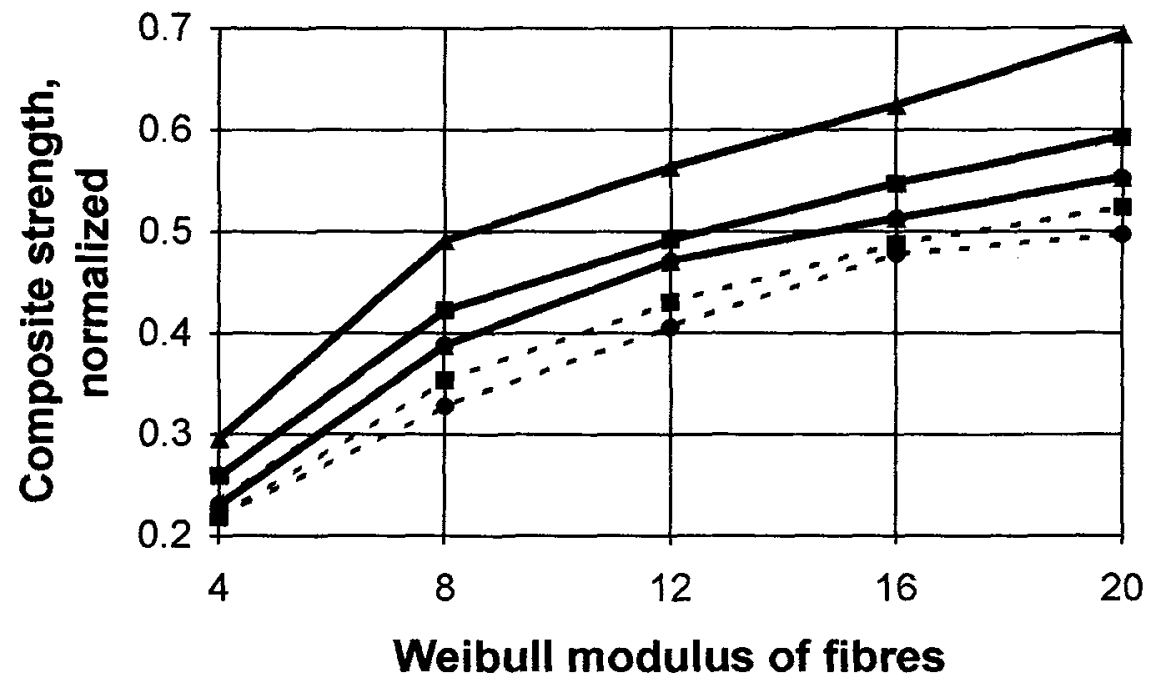

Figure 5:

Composite strength normalized to $\sigma_{0}\left(1_{e}\right) V_{F}$ as a function of the Weibull modulus of the fibres.

A: $\mathrm{mn}=10^{6}$

口: $\mathrm{mn}=10^{9}$

- $\mathrm{mn}=10^{12}$ $: P=0.63$ $\ldots . . P=10^{-6}$

Figure 6 shows the critical cluster size which causes the break of the composite. The critical cluster size is only an average. Smaller cluster can also cause the break if there are particularly weak fibres in the vicinity while larger cluster do not cause the break if neighbour fibres are very strong. Comparing figures 5 and 6 , composites containing fibres with a high Weibull modulus have a high strength but a small cluster of locally broken fibres causes the crack. The strength and critical cluster size for a large composite at a high failure probability $\left(\mathrm{mn}=10^{12}, \mathrm{P}=0.63\right)$ are almost the same as for a small composite at a low failure probability 
$\left(\mathrm{mn}=10^{6}, \mathrm{P}=10^{-6}\right)$. Thus the normalized strength of composites with the same ratio $\mathrm{mn} / \mathrm{P}$ and the same Weibull modulus of the fibres is equal.

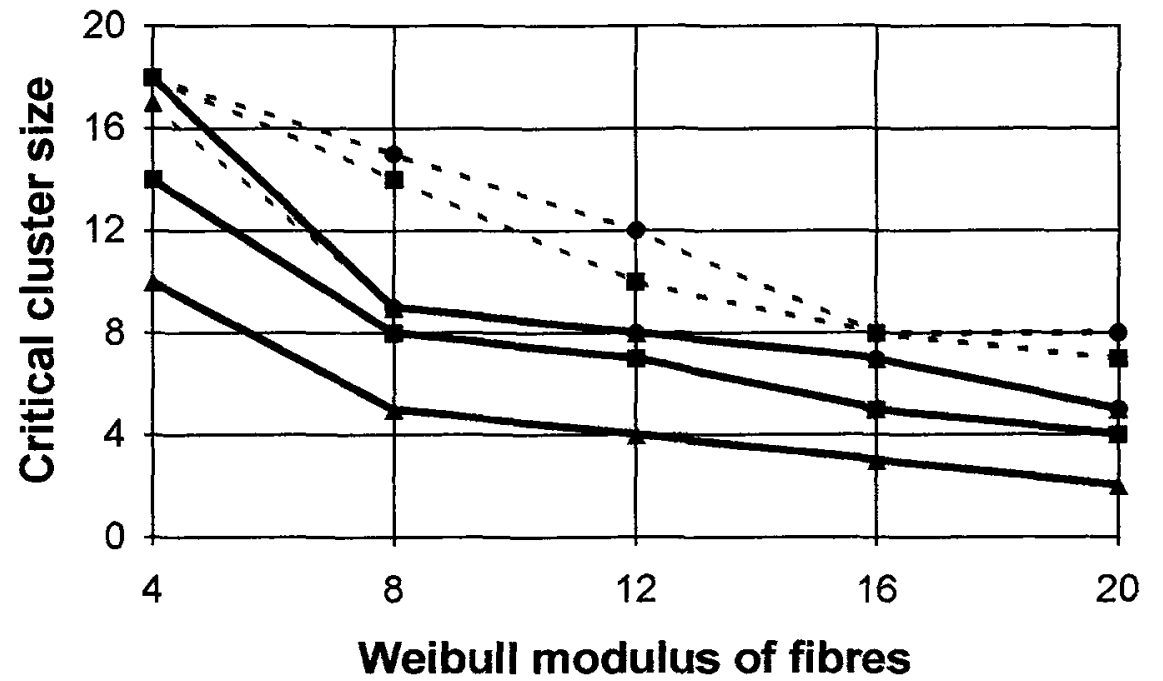

Figure 6:

Critical cluster size versus Weibull modulus for different sizes and failure probabilities of the composite.

A: $\mathrm{mn}=10^{6}$
$\mathbf{m n}=10^{9}$
$: \mathrm{mn}=10^{12}$

$\longrightarrow: P=0.63$

The Weibull modulus of the composite strength measured in an experiment with a few samples would occur to be constant, because only a small part of the Weibull diagram is examined (fig. 4). This measured Weibull modulus is about equivalent to the slope of the predicted curve in the Weibull diagram at a failure probability of $P=0.63$, which is the critical cluster size times the Weibull modulus of the fibres [6]: $\rho_{\text {composite }} \approx \mathrm{k}^{*} \rho_{\text {fibres. }}$

\section{ACKNOWLEDGEMENTS}

The authors thank Prof. Peter Schwartz, Cornell University, for reviewing the manuscript.

\section{REFERENCES}

[1] KELLY, A., TYSON, W.R., Mech. Phys. Sol. (1965) 19, 329.

[2] ROSEN, W., AIAA Journal (1964) 1985.

[3] FUKUDA, H., KAWATA, K., Fibr. Sci. Tech. (1977) $10,53$.

[4] MANDERS, P.W., BADER, G., CHOU, T.-W., Fibr. Sci. Tech. (1982) 17, 183.

[5] SMITH, R.L., PHOENIX, S.L., GREENFIELD, M.R., HENSTENBURG, R.B., PITT, R.E., Proc. R. Soc. London (1983) A388, 353.

[6] PHOENIX, S.L., SMITH, R.L., Int. J. Sol. Struct. (1983) 19, 479.

[7] LIENKAMP, M., SCHWARTZ, P., Comp. Sci. Tech. (1993) 46, 139.

[8] BADER, M.G., Proc. Europ. Conf. Damage Development and Failure Processes in Composite Materials. Leuven (B) (1987) 8.

[9] HEDGEPETH, J.M., VAN DYKE, P., J., Comp. Mat. (1967) 1, 294.

[10] WEIBULL, W., Ing. Vetenskaps. Akad. Handl., Stockholm (1939) 1.

[11] CHI, Z., CHOU, T.-W., SHEN, G., J. Mat. Sci. (1984) 19, 3319.

[12] LIENKAMP, M., EXNER, H.E., Z. Metallkd. (1993) 84, 286.

[13] HERRERA-FRANCO, P.J., DRZAL, L.T., Composites (1992) 23, 2.

[14] LIENKAMP, M., First Forum of Young European Researchers (18-23 July 1993) Liege, Belgium, submitted.

[15] DANIELS, H.E., Proc. R. Soc. London (1945) 183A, 405. 